\title{
Reading comprehension on word- and sentence-level can be predicted by orthographic knowledge for German children with poor reading proficiency
}

\author{
Jelena Zarić ${ }^{1}$ D $\cdot$ Telse Nagler ${ }^{2}$
}

Accepted: 9 January 2021 / Published online: 13 February 2021

(C) The Author(s) 2021

\begin{abstract}
Previous studies mostly examined the role of orthographic knowledge in basic reading processing (i.e., word-reading), however, regarding higher reading processing (i.e., sentence- and text-comprehension), mixed results were reported. In addition, previous research in transparent languages, such as German, focused mostly on typically skilled readers. The aim of this study was to examine the role of orthographic knowledge in basic reading processing (word-reading) as well as in higher reading processing (sentence- and text-comprehension), in addition to phonological awareness and naming speed in a sample of German elementary school poor readers. For this purpose, data from 103 German third-graders with poor reading proficiency were analyzed via multiple linear regression analysis. Analyses revealed that orthographic knowledge contributes to reading at word- and sentence-level, but not at text-level in German third-graders with poor reading proficiency, over and above phonological awareness and naming speed. These findings support that orthographic knowledge should be considered as a relevant reading related predictor. Therefore, it would be reasonable to include the assessment of orthographic knowledge skills in diagnostic procedures to identify children at risk to develop reading difficulties, besides phonological awareness and naming speed.
\end{abstract}

Keywords Orthographic knowledge $\cdot$ Phonological awareness $\cdot$ Naming speed Reading $\cdot$ Poor readers

Jelena Zarić

jelena.zaric@dipf.de

1 DIPF I Leibniz Institute for Research and Information in Education, Rostocker Str. 6, 60323 Frankfurt, Germany

2 Center for Individual Development and Adaptive Education of Children At Risk (IDeA), Frankfurt, Germany 


\section{Introduction}

Reading is one of the most important academic skills in our society. However, some children struggle to reach sufficient reading proficiency during and after elementary school education. Between 3 and $8 \%$ of the children show serious difficulties in acquiring adequate reading skills (e.g., Landerl \& Moll, 2010; Moll, Kunze, Neuhoff, Bruder, \& Schulte-Körne, 2014). Difficulties in reading can lead to limited education, resulting in higher chance of unemployment as well as financial and economic disadvantages (Valtin, 2017; Vellutino et al., 1996). Also, there is a higher risk for children with reading difficulties to develop comorbid psychological problems, such as social phobia or depression (e.g., Bäcker \& Neuhäuser, 2003; Carroll, Maughan, Goodman, \& Meltzer, 2005; Willcutt \& Pennington, 2000). To counter such unfavorable development, identification of factors relevant for (un)successful reading proficiency, as well as development and improvement of instruments for recognizing children at risk are crucial (Castles, Rastle, \& Nation, 2018; Tippelt \& Schmidt-Hertha, 2018).

It is widely accepted that reading includes a variety of processes, which differ in their complexity. These processes include identifying written words, comprehending sentences, and also establishing coherence between sentences (Perfetti, Landi, \& Oakhill, 2005; Vellutino, Fletcher, Snowling, \& Scanlon, 2004). In this paper, we focus on the processing steps necessary for understanding a text while concentrating on different complexity levels, including basic level (i.e., word-reading) and higher level (i.e., sentence- and text-level comprehension; see Lenhard \& Schneider, 2006). The word level represents the basic level of reading, which includes decoding of single words and understanding the meaning of the words (Castles et al., 2018; Karageorgos, Müller, \& Richter, 2019). Single word reading is mostly associated with lower level processing skills, such as fast and efficient orthographic and phonological processing and identification (Wolf $\&$ Katzir-Cohen, 2001). In an often cited model of reading processes (i.e., Dual Route model; Coltheart, Curtis, Atkins, \& Haller, 1993), word reading proceeds in two different ways via (1) lexical or (2) non-lexical route. When confronted with frequent and/or familiar words, representations of words and letter patterns stored in the mental lexicon can be retrieved automatically via the lexical route. When confronted with low frequent and/or unfamiliar words, letter-to-soundconversion via the non-lexical route is applied. Especially in orthographically consistent languages, such as Greek, Finnish, Italian, or German, children who are learning to read rely more on letter-to-sound recoding because the relationship between letters and sounds is straightforward (Ziegler \& Goswami, 2005). Skilled readers are characterized by increased use of the lexical, more efficient route during reading. The automatized word decoding processes free up cognitive resources which can then be used for higher-demanding processes, such as comprehension processes at the sentence and text level (Perfetti \& Hart, 2002; Pikulski \& Chard, 2005; Roberts, Good, \& Corcoran, 2005). Less skilled readers use the non-lexical, less efficient route more often, resulting in decreased reading fluency and therefore impaired reading comprehension (Fuchs, Fuchs, Hosp, 
\& Jenkins, 2001). In addition, at the word level, poor readers show difficulties in their decoding skills compared to good readers (Cain, 2009).

The successful identification of the words, interpretation of their meaning in the given context as well as the integration between different words enable reading comprehension at higher level (i.e., sentence-level; Lenhard \& Schneider, 2006). In order to understand the content of the sentence it is necessary to analyze semantic and syntactic elements within the sentence (Richter \& Christmann, 2002). The processing of the semantic and syntactic elements is assumed to run parallel, and enables the understanding of the content of the sentence (Lenhard \& Schneider, 2006; Taraban \& McClelland, 1990). At the sentence-level, poor readers seem to have lower syntactic knowledge and they show more problems in creating a coherent representation of related sentences compared to skilled readers (Cain, 2009).

The last level of reading we want to examine in this study is text-level comprehension, defined as an understanding of the relationship between different sentences, which enables the processing of texts (Gough \& Tunmer, 1986; Lenhard \& Schneider, 2006). Successful text-level comprehension processes therefore include extraction of information, establishing cross-reference (anaphoric) connections, and also drawing inference conclusions (in a sense of "reading between the lines"; Lenhard $\&$ Schneider, 2006). At the text-level, poor readers seem to have problems in building a situational model described in the text due to the problems in generating textbased inferences, and they seem to have problems integrating the propositions from the text with their own prior knowledge (Cain, 2009).

To sum up, efficient word-level reading frees up cognitive resources which are then available for sentence- and text-level comprehension (Perfetti \& Hart, 2002). Since word-level reading is mostly associated with lower level processing skills, such as fast and efficient retrieval as well as orthographic and phonological processing and identification, it is important to have a closer look at skills relevant for reading. In this respect, especially the automatized and fast retrieval of information (i.e., naming speed), the quality of orthographic representations and access to linguistic information stored in the mental lexicon (i.e., orthographic knowledge) as well as the awareness of the sound structure of the language (i.e., phonological awareness) have shown to be important for reading operations.

\section{Phonological awareness, naming speed, and orthographic knowledge}

Following the assumptions of automatic information processing theories (LaBerge \& Samuels, 1974; Perfetti, 1985), phonological awareness, naming speed and orthographic knowledge are considered to be highly interrelated, however, independent contributors to reading. An efficient representation retrieval from the mental lexicon due to established pathways facilitates and accelerates decoding processes, thus, free cognitive resources can be used for higher processes, such as reading comprehension. This fast and efficient retrieval is, however, only achievable, if direct word identification is possible (Thaler, Ebner, Wimmer, \& Landerl, 2004) via the lexical route from the mental lexicon. If the direct retrieval is not available, phonological awareness helps to translate print into words via the less automatized and less 
efficient letter-by-letter identification through phonological re- and decoding processes. However, this impedes the storing of commonly occurring orthographic patterns and representations. As a result, inefficient, slow recognition of orthographic patterns can lead to slower reading rate (Wolf \& Bowers, 1999) and difficulties in reading comprehension (Landerl \& Wimmer, 2008). As suggested by the orthographic depth hypothesis (Katz \& Frost, 1992), the letter-to-sound consistency of the language influences the degree to which readers rely on phonological or orthographic information. In opaque languages (such as English or French) readers rely more on the visual-orthographic structure of printed words to overcome decoding difficulties resulting from ambiguous and partly inconsistent letter-to-sound correspondences. In transparent languages (such as German or Greek) with consistent letter-to-sound correspondences readers rely more on more easily available phonological information (Ise, Arnoldi, \& Schulte-Körne, 2014).

\section{Phonological awareness}

Phonological awareness enables the recognition and manipulation of sound units of the spoken language (e.g., Anthony \& Francis, 2005; Steinbrink \& Lachmann, 2014). Therefore, it is considered as a prerequisite of early decoding development, with an impact on later reading comprehension (Vellutino, Tunmer, Jaccard, \& Chen, 2007). A large body of research supports the predictive value of phonological awareness for the acquisition of reading skills (e.g., Ennemoser, Marx, Weber, \& Schneider, 2012; Heath \& Hogben, 2004; Moll, Fussenegger, Willburger, \& Landerl, 2009). A recent meta-analysis by Pfost (2015) identified phonological awareness as a significant predictor for reading speed, reading accuracy, and reading comprehension. However, the differences in letter-to-sound correspondences in transparent vs. opaque languages have been shown to lead to different impacts of phonological awareness on reading (see Ziegler et al., 2010). In transparent orthographies, the differences in preliterate phonological awareness become homogenized more quickly due to consistent letter-to-sound connections than in opaque languages, leading to weaker correlations between phonological awareness and reading in transparent languages (Ziegler et al., 2010). It is assumed that deficits in phonological awareness lead to difficulties in building and storing associations between phonological and orthographic representations in the mental lexicon, thus, evoking difficulties in reading acquisition (Landerl \& Thaler, 2006; Scheerer-Neumann, 2015). Children with reading difficulties also show deficits in different aspects of phonological awareness, such as segmentation and phoneme deletion tasks (e.g., "say the word 'mouth' without /m/"; Melby-Lervåg, Lyster, \& Hulme, 2012; Paulesu et al., 2001; Ramus et al., 2003).

\section{Naming speed}

Naming speed is considered as a basic cognitive process which influences reading speed development (Moll, Wallner, \& Landerl, 2012). It is usually measured by rapid automatized naming (RAN) tasks requiring the speeded naming of lists of familiar stimuli, such as letters, pictured objects, color patches, and digits (Denckla 
\& Rudel, 1976). Typical tasks used to measure reading at the word-level, such as tasks focusing on word reading speed and/or pseudoword (i.e., pronounceable letter combinations, created by using certain linguistic criteria) reading as well as tasks measuring reading accuracy and speed, are usually correlated with or predicted by RAN measures (e.g., Bowers, 1995; Georgiou, Parrila, \& Papadopoulos, 2008; Landerl \& Wimmer, 2008; Moll et al., 2009). Furthermore, several studies reported that RAN is also correlated with or predicts reading comprehension measures (e.g., Arnell, Joanisse, Klein, Busseri, \& Tannock, 2009; Georgiou, Das, \& Hayward, 2008; Kirby, Parrila, \& Pfeiffer, 2003; McCallum et al., 2006). It is assumed that in consistent orthographies where readers decode words by applying letter-tosounds conversion rules (e.g., Goswami, 2002), naming speed is strongly related to reading because the phonological representation of graphemes must be retrieved quickly for letter-to-sound conversion to be effective (Georgiou, Parrila et al., 2008). Children with reading and spelling difficulties show slower naming speed in the RAN tasks compared to unimpaired controls (e.g., Georgiou, Papadopoulos, Fella, \& Parrila, 2012; Wimmer, 1993).

\section{Orthographic knowledge}

Orthographic knowledge is considered as one of the major individual prerequisites of word identification (Cutting \& Denckla, 2001), which contains specific sequences of graphemes representing written words (i.e., mental graphemic representations; Apel, 2011). In order to accurately identify a word, it is crucial to know how letters are combined to form a specific word (Apel, 2011; Loveall, Channell, Phillips, \& Conners, 2013). Hence, fluent reading is supported by a sufficient level of orthographic knowledge, which enables the individual to quickly recognize written words with little cognitive effort (e.g., Ehri, 2005; 2014). In transparent languages, such us Dutch, repeated blending of graphemes and phonemes during decoding leads to successful phonological recoding, and enables establishment of orthographic representations (De Jong \& Messbauer, 2011), which are crucial for developing fluent reading (Rothe, Cornell, Ise, \& Schulte-Körne, 2015).

There are several different definitions of orthographic knowledge in the literature. In this paper, we use the term orthographic knowledge consistent with Apel (2011), where both the ability to develop and access mental representations of written words in the mental lexicon (i.e., word-specific orthographic knowledge) as well as the application of knowledge about rules and word patterns (i.e., general orthographic knowledge) are included. Word-specific or lexical orthographic knowledge involves the stored mental representations of familiar words and word parts. Tasks used to measure word-specific orthographic knowledge usually involve words and pseudohomophones decision tasks, where children have to actively think or reflect on their knowledge of orthography and decide whether the presented stimuli is a real word or not by comparing it to the orthographic representation stored in the mental lexicon (e.g., Apel, Henbest, \& Masterson, 2018). General or sub-lexical orthographic knowledge contains knowledge about the rules and legal letter patterns of a writing system, including the rules that govern where certain letters can occur in word positions, and what letters can be combined with another (Apel et al., 2018). General 
orthographic knowledge is typically measured by orthographic word-likeness task, where children are asked to choose the one pseudoword that most reassembles a real word. One pseudoword in these tasks follows legal orthographic conventions whereas the other violates them. For instance, these tasks measure children's knowledge of permissible orthographic patterns, word position rules, and/or orthographic sequence rules (Apel et al., 2018). With these tasks, the children's knowledge of allowable orthographic patterns is measured rather than the explicit use of that knowledge during reading or spelling. Children with reading and spelling difficulties show lower scores in the tasks measuring word-specific (Bergmann \& Wimmer, 2008) and general orthographic knowledge compared to their typically reading peers (Rothe et al., 2015).

Several studies revealed that word-specific and general orthographic knowledge contribute to word-reading skills (e.g., Arab-Moghaddam \& Sénéchal, 2001; Bergmann \& Wimmer, 2008; Georgiou, Parrila et al., 2008; Rothe et al., 2015; Rothe, Schulte-Körne, \& Ise, 2014). In previous studies examining the role of orthographic knowledge in reading performance, typical tasks used to measure reading skills included real word/pseudoword reading and/or reading fluency, however, without including any higher reading processes, such as reading comprehension (Apel et al., 2018). To our knowledge, there are only few studies examining the relationship between orthographic knowledge and both reading at word-level and sentenceand/or text-level simultaneously in transparent languages with relatively consistent letter-to-sound-correspondences, such as German (e.g., Ise, Arnoldi, \& SchulteKörne, 2014; Zarić, Hasselhorn, \& Nagler, 2020). Ise et al. (2014) have shown no significant correlations between orthographic knowledge and reading speed and comprehension in children from kindergarten to 2 nd grade. In the reading task used by Ise et al. (2014), children are presented with simple sentences and are asked to read them silently as quickly as possible, and to indicate whether the content of the sentence is generally false or true. In this study, however, only one task measuring orthographic knowledge at the general level (i.e., the knowledge about frequent and infrequent double consonants) was used. Another study conducted in German by Zarić et al. (2020), however, reported that word-specific and general orthographic knowledge show significant correlations with reading at word-, sentence, and textlevel. Moreover, the analyses have shown that both word-specific and general orthographic knowledge are significant predictors for reading at word-level, as well as at sentence- and text-level in German $3^{\text {rd }}$ graders without reading difficulties. Since reading accuracy reaches ceiling at the end of Grade 1 in transparent languages (Seymour, Aro, \& Erskine, 2003), age differences between the examined samples in these two studies might have an influence on different result patterns. In addition, the differences in the tasks used to measure orthographic knowledge and reading performance might explain differences in the findings.

To sum up, it still remains unclear whether orthographic knowledge with its two components (i.e., word-specific and general) contributes to sentence- and textlevel reading in German. Furthermore, the previous studies regarding the contribution of word-specific and general orthographic knowledge at sentence- and textlevel reading in German examined typical readers (Ise et al., 2014; Zarić et al., 2020). Therefore, it is still unclear whether both subtypes of orthographic knowledge 
(i.e., word-specific and general) also contribute to reading at sentence- and text-level in German poor readers.

\section{The present study}

Phonological awareness and naming speed have shown to be important predictors for basic as well as for higher reading processes (e.g., Kirby et al., 2003; Landerl \& Wimmer, 2008; Pfost, 2015). Word-specific and general orthographic knowledge, on the contrary, were mostly examined in basic reading skills (i.e., word and/or pseudoword reading; e.g., Conrad et al., 2013; Rothe et al., 2015). Regarding higher reading skills (i.e., sentence- and text-level reading), mixed results were reported (Ise et al., 2014; Zarić et al., 2020).

Previous studies in German examining the role of orthographic knowledge in basic and higher reading processes simultaneously included samples of children without reading difficulties. However, studies with different samples (i.e., with and without reading difficulties) report different results (e.g., different correlations for impaired and non-impaired readers) regarding the relationship between reading and components relevant for reading (i.e., phonological awareness, RAN, orthographic knowledge; e.g., Swanson, Trainin, Necoechea, \& Hammill, 2003). Therefore, the results from studies examining children without reading difficulties cannot be generalized to children with reading difficulties. Thus, it is important to examine the role of orthographic knowledge to reading in children with reading difficulties as well, as anticipated in the present study. A large body of research also suggests that the course of reading acquisition and the deficits underlying reading difficulties might differ across orthographies (Ziegler \& Goswami, 2005). Thus, findings from opaque languages, such as English, cannot be transferred onto more transparent languages, such as German, which is in focus of the present study.

The aim of this study is to address the gaps in past empirical research by exploring the relationship between word-specific and general orthographic knowledge and reading at basic reading level (i.e., word-level), as well as at higher reading level (i.e., sentence- and text-level) in German elementary school poor readers. Since word-specific and general orthographic knowledge seem to play an important role in word-identification, it can be assumed that children with low reading proficiency use their orthographic knowledge when reading single words. Therefore, in line with previous results (e.g., Rothe et al., 2015; Zarić et al., 2020), we hypothesize that word-specific and general orthographic knowledge contribute significantly to reading at word-level, over and above the contribution of phonological awareness and naming speed in poor readers.

Furthermore, following the assumption that high-quality orthographic representations are necessary for higher reading processes, like reading comprehension (see for example the Lexical Quality Hypothesis; Perfetti \& Hart, 2002), it is assumed that word-specific and general orthographic knowledge can contribute to efficient single-word reading, enabling their processing, and therefore enhancing reading fluency, resulting in comprehension at sentence- and text-level. Thus, we hypothesize that word-specific and general orthographic knowledge also contribute to reading 
comprehension at sentence- and text-level, in addition to phonological awareness and naming speed in poor readers.

\section{Method}

\section{Participants}

In a screening at 13 schools with a total of 484 participants, 103 German thirdgraders (mean age $=8.87$ years, $S D=0.48,46.6 \%$ girls; average IQ, mean $=102.36$, $S D=11.06)$ from 10 public elementary schools in Frankfurt/Main in Germany were identified to meet the criteria to participate in the study: (1) reading performance $\leq 30^{\text {th }}$ percentile in a standardized reading test; Würzburger Leise LeseprobeRevision ${ }^{1}$ [WLLP-R; Würzburger silent reading test-revised]; Schneider, Blanke, Faust, \& Küspert, 2011); (2) average and above average non-verbal intelligence $(85 \leq \mathrm{IQ} \leq 130)$ assessed by a standardized test (Zahlen-Verbindungs-Test, ZVT; [A trail making test]; Oswald \& Roth, 1987). Parental consent was obtained for each child. The study was approved by a research ethics board.

\section{Materials}

\section{Decoding speed (WLLP-R)}

To identify poor readers in a screening process, the standardized WLLP-R (Schneider et al., 2011) reading test was used in the present study. ${ }^{2}$ This paper-pencil test measures decoding speed. Participants are asked to choose one out of four pictures that corresponds to the word presented as fast as possible within a time-limit of five minutes. The authors report good parallel-test reliability $(r=0.93)$.

\section{Reading at word-, sentence-, and text-level}

Reading performance was assessed using the computer version of a standardized German reading test (Ein Leseverständnistest für Erst- bis Sechstklässler-ELFE 1-6; [A reading comprehension test for first- till sixth-graders]; Lenhard \& Schneider, 2006). This test is divided into three subtests and measures reading at word-, sentence-, and text-level with a time-limitation. Reading at word-level is measured through 72 items composed of a picture accompanied by four-word alternatives. Participants have to choose the word corresponding to the picture. The subtest for measuring reading comprehension at sentence-level contains 28 sentences. Participants are asked to complete the sentences by choosing one out of five possible word

\footnotetext{
1 WLLP-R T-value mean of the sample $=26,55(S D=5,28)$; the decoding speed $\leq 30$ th percentile was used as an inclusion criterion, thus, children with severe as well as mild reading problems are considered, without including the clinical definition of reading impairment.

2 The WLLP-R percentile range from $0-30^{\text {th }}$ percentile in the sample.
} 
alternatives. For measuring reading comprehension at text-level, participants are asked to process 20 items comprising a connected text and a corresponding multiple- choice question. According to the authors the three subtests show high internal consistency (word-level $\alpha=0.97$, sentence-level $\alpha=0.93$, and text-level $\alpha=0.97$ ). Standardized T-scores of each of the three subtests were used for further statistical analyses.

\section{General (non-verbal) intelligence}

For assessing participant's general (non-verbal) intelligence a standardized test (ZVT; Oswald \& Roth, 1987) was used. The test contains four matrices with different configurations of digits from 1 to 90 . Participant are instructed to connect the digits in the counting order as fast as possible within a time limit of 30 seconds per matrix. The authors report that this test measures cognitive speed of processing, and can be therefore considered to represent a basic (general) and non-verbal component of intelligence, classified by the indication of intelligence quotient (IQ) scores. The retest-reliability data vary from $r_{\mathrm{tt}}=0.84$ to $r_{\mathrm{tt}}=0.97$. For further statistical analyses, IQ-scores provided by the manual were used.

\section{Phonological awareness}

Phonological awareness was measured by the subtest of a German sound differentiation test (Heidelberger Lautdifferenzierungstest-H-LAD; [Heidelberg sound differentiation test]; Brunner, Seibert, Dierks, \& Körkel, 1999). Participants are instructed to decide whether they hear two same or two different words/syllables for each of the 32 items (23 word-pairs and 9 syllable-pairs). Authors report internal consistency between $\alpha=0.86$ and $\alpha=0.88$. In addition, satisfying correlations $(r=0.61$ for the $2^{\text {nd }}$ grade; $r=0.54$ for the $4^{\text {th }}$ grade) with a sound differentiation and auditive memory test (see Mottier-Test; Linder \& Grissemann, 2000) were found, supporting H-LAD's convergent validity. Standardized T-scores were used for further analyses.

\section{Naming speed}

Naming speed was assessed by using four RAN-task-matrices in DIN-A3 format, each containing either objects (candle, car, dog, fish, hammer), colors (blue, green, red, yellow, black), letters (f, k, r, s, t), or digits (1, 4, 5, 6, 8; see also Denckla \& Rudel, 1976). In this RAN task, participants are instructed to name the presented stimuli as fast and as accurately as possible. Time required for each of the four matrices as well as the number of errors was measured. For further analyses, the processing time of the correctly named items of all four subtests was summarized into an overall RAN sum score.

\section{Orthographic knowledge}

To assess orthographic knowledge at the word-specific and general-level, new item sets according to the construction principles of previous studies (e.g., Rothe et al., 
2015; Zarić et al., 2020) were generated. For item development, the child-oriented childLex database (Schroeder, Würzner, Heister, Geyken, \& Kliegl, 2015) was used. The tasks measuring word-specific and general orthographic knowledge were programmed in Psychology software in Python (PsychoPy; Peirce, 2009) and were presented on a laptop with 14.1-in. monitor on a black screen with white letters in font size 35 .

Word-specific orthographic knowledge was measured by using an orthographic decision task, consisting of 30 self-developed individually and randomly presented items (15 real words and 15 pseudohomophones-i.e., a constructed word with the same pronunciation as an existing word, however, incorrectly spelled, e.g., rainrane) and two practice items (see Appendix, Table 4). Pseudohomophones were developed by manipulating real words (e.g., by alternating the letters /ä/ and /e/: bärtig-bertig), which were similarly pronounceable. The selected words used for creating pseudohomophones, as well as all selected real words, were low frequent. ${ }^{3}$ To assess word-specific orthographic knowledge children were asked to decide whether the presented item was a real word or not by pressing the corresponding button on a computer keyboard.

General orthographic knowledge was assessed using an orthographic-choice task, consisting of 20 self-developed randomly presented test items and two practice items (see Appendix, Table 5). Each item contained two pronounceable pseudowords (i.e., pronounceable letter combinations, created by using legitimate linguistic criteria) with six letters. The test items measured the knowledge about the legal positions of double consonants in German. One pseudoword in each pair contained a double consonant in a legal position (e.g., lannag, fahopp), and the other contained a double consonant in an illegal position (e.g., ffosup). The frequency of all bigrams ${ }^{4}$ and trigrams ${ }^{5}$ was controlled for all test items and were comparable for pseudowords containing double consonants in a legal position and pseudowords containing double consonants in an illegal position (see Appendix, Table 5). Children were asked to choose which of the two presented pseudowords closest resembles a real German word and to press the corresponding button on a computer keyboard.

\section{Procedure}

Participants were tested on three days during regular school times in the morning. Trained examiners conducted the different tasks and ensured a child-appropriate atmosphere with enough brakes during the testing periods. On the first day (screening day), a total of 484 participants were first asked to complete the trail-making-test

\footnotetext{
3 Type frequency of the selected words was $\leq 500$ times per million continuous words in the corpus, and were therefore classified as low frequent in comparison to other words..

${ }^{4} U=193.00, p=.85$; no significant difference between bigram frequencies of the pseudowords containing double consonants in the legal vs. pseudowords containing double consonants in illegal position.

$5 U=154.00, p=.21$; no significant difference between trigram frequencies of the pseudowords containing double consonants in the legal vs. pseudowords containing double consonants in illegal position.
} 
(ZVT; Oswald \& Roth, 1987) in a classroom setting. Afterwards, they completed the standardized German reading test (WLLP-R; Schneider et al., 2011). After the screening day, the children who were identified to meet the criteria to participate in the study were tested on the second and third test day. The second test day was realized in smaller group settings (up to 12 persons). The participants first completed the standardized German reading test ELFE 1-6 (Lenhard \& Schneider, 2006), followed by the standardized phonological awareness task H-LAD (Brunner et al., 1999). Subsequently, participants conducted the tasks measuring the word-specific and general orthographic knowledge. On the third day participants completed the RAN task (see also Denckla \& Rudel, 1976) in a single-participant test situation.

\section{Data preparation}

For each of the four RAN subtest (i.e., colors, digits, letters, and objects) errors ${ }^{6}$ were subtracted from the total sum of the items per subtest (50), providing the number of correctly named items per subtest. Then, the total time of all four subtest was divided by all correctly named items, providing the total average naming speed (items per second) for all four subtests together. This RAN measure was subsequently used for further statistical analyses.

Before running statistical analyses regarding orthographic knowledge data, an item-analysis for the items measuring word-specific and general orthographic knowledge was conducted. The analysis regarding the items measuring word-specific orthographic knowledge revealed that several items had a poor degree of selectivity $(\leq 0.02)$ and difficulty $(\leq 0.30$ and $\geq 0.87)$, and therefore, these items were excluded from further calculations. With the remaining 16 items this task revealed to have a sufficient internal consistency (Cronbach's $\alpha=0.72$ ). The raw score of the task measuring word-specific orthographic knowledge represents the number of correct answers (see Appendix, Table 4). The analysis regarding the items measuring general orthographic knowledge also revealed several items with poor degree of selectivity $(\leq 0.10)$ and difficulty $(\geq 0.87)$. The number of correct answers of the remaining 16 out of 20 items of the task measuring general orthographic knowledge represents its raw score (see Appendix, Table 5) with a sufficient internal consistency (Cronbach's $\alpha=0.77$ ).

\section{Results}

Means and standard deviations for all measures used in the current study for the entire sample $(\mathrm{N}=103)$ included are presented in Table 1.

\footnotetext{
${ }^{6}$ Subtest color-naming: mean error $=.45, \mathrm{SD}=.69$ (range 0-3); subtest digit-naming: mean error $=.14$, $\mathrm{SD}=.54$ (range $0-5$ ); subtest letter-naming: mean error $=.53, \mathrm{SD}=1.55$ (range $0-10$ ); subtest objectnaming: mean error $=.30, \mathrm{SD}=.84$ (range $0-7)$.
} 
Table 1 Means and standard deviations of all measures

\begin{tabular}{lll}
\hline & Mean & $\begin{array}{l}\text { Standard } \\
\text { deviation }\end{array}$ \\
\hline Phonological awareness & $43.77^{\mathrm{a}}$ & 9.99 \\
RAN & $0.86^{\mathrm{b}}$ & 0.13 \\
Word reading & $40.33^{\mathrm{a}}$ & 7.60 \\
Sentence reading & $38.47^{\mathrm{a}}$ & 6.82 \\
Text reading & $42.29^{\mathrm{a}}$ & 7.78 \\
Word-specific orthographic knowledge & $8.06^{\mathrm{c}}$ & 3.25 \\
General orthographic knowledge & $11.91^{\mathrm{c}}$ & 3.35 \\
\hline
\end{tabular}

RAN, rapid automatized naming

${ }^{\mathrm{a}} \mathrm{T}$-score

${ }^{b}$ Average reaction time per correct item per second of the four RAN subtests

${ }^{\mathrm{c}}$ Raw score (maximum 16)

Table 2 Intercorrelations between reading measures, phonological awareness, RAN, and word-specific and general orthographic knowledge

\begin{tabular}{llllllll}
\hline & 1 & 2 & 3 & 4 & 5 & 6 & 7 \\
\hline 1. Word-level & - & & & & & & \\
2. Sentence-level & $.73^{* *}$ & - & & & & \\
3. Text-level & $.33^{* *}$ & $.48^{* *}$ & - & & & \\
4. Phon. awareness & $.19^{*}$ & $.30^{* *}$ & $.40^{* *}$ & - & & \\
5. RAN & $-.37^{* *}$ & $-.21^{*}$ & -.11 & -.06 & - & & \\
6. Word-specific orth. know & $.28^{* *}$ & $.22^{* *}$ & .15 & .11 & -.10 & - & \\
7. General orth. know & $.26^{*}$ & $.22^{*}$ & .13 & -.06 & -.15 & $.21^{*}$ & - \\
\hline
\end{tabular}

$* p \leq .05 ; * * p \leq .01 ;$ phon.$=$ phonological; RAN $=$ Rapid automatized naming; orth. know. =orthographic knowledge

\section{Relationship between reading measures, phonological awareness, naming speed, and orthographic knowledge}

In Table 2 correlations between word-specific and general orthographic knowledge, phonological awareness, naming speed, and reading at word-, sentence-, and textlevel (based on ELFE 1-6) are shown. Since RAN, word-specific and general orthographic knowledge, and phonological awareness violated the normal distribution, we report Spearman's Rho $\mathrm{r}_{\mathrm{s}}$ correlation coefficients.

Word-specific and general orthographic knowledge, phonological awareness and naming speed significantly correlated with reading at word- and sentence-level. There was no significant correlation between reading at text-level and word-specific and general orthographic knowledge, and naming speed. However, phonological awareness significantly correlated with reading at text-level. In addition, there were no significant correlations between phonological awareness, naming speed and 
word-specific and general orthographic knowledge. Reading at word-, sentence-, and text-level correlated significantly. Word-specific and general orthographic knowledge showed significant correlations.

\section{Predictive patterns of word-specific and general orthographic knowledge for reading measures}

Multiple hierarchical regression analyses were conducted to explore whether wordspecific and general orthographic knowledge explain unique variance in reading at word-, sentence-, and text-level. To explore the two subtypes independently of each other, separate regression models for word-specific (Model 1) and general orthographic knowledge (Model 2) for reading at word-, sentence-, and text-level were calculated. In addition, both subtypes of orthographic knowledge were entered simultaneously into the regression model (Model 3). In all regression models (Model 1, Model 2, and Model 3, see Table 3), ${ }^{7}$ phonological awareness and RAN were entered in Step 1. In Step 2 word-specific (Model 1) or general orthographic (Model 2) knowledge, or both word-specific and general orthographic knowledge (Model 3) were entered to explore the unique amount of explained variance of orthographic knowledge, over and above phonological awareness and naming speed. Although the predictor variables violated the normal distribution, the residuals showed normal distribution, thus, indicating homoscedasticity.

\section{Reading at basic level}

The analyses show that phonological awareness and naming speed are both significant predictors for reading performance at basic level (i.e., word-level), and together they explain $18 \%$ of variance of word-level reading performance. After entering word-specific and/or general orthographic knowledge into the regression model, both phonological awareness and naming speed remain significant predictors. Wordspecific orthographic knowledge explains additional $4 \%$ of variance of reading at word-level (Table 3, Model 1, column Word-level). General orthographic knowledge explains additional 5\% of variance of word-level reading (Table 3, Model 2, column Word-level). Together, word-specific and general orthographic knowledge explain additional $7 \%$ of variance of reading at word-level, over and above explained variance by phonological awareness and naming speed.

\section{Reading at higher level}

The results show that phonological awareness and naming speed are both significant predictors for reading performance at sentence-level, and together they

\footnotetext{
7 The same regression analyses were performed for the subpopulation of really poor readers with a reading proficiency below the $16^{\text {th }}$ percentile. The results are presented in the Appendix, Table 6. In general, the results from this subpopulation differ slightly from the results of the whole sample, however, due to a smaller sample size, the statistical power was lower.
} 


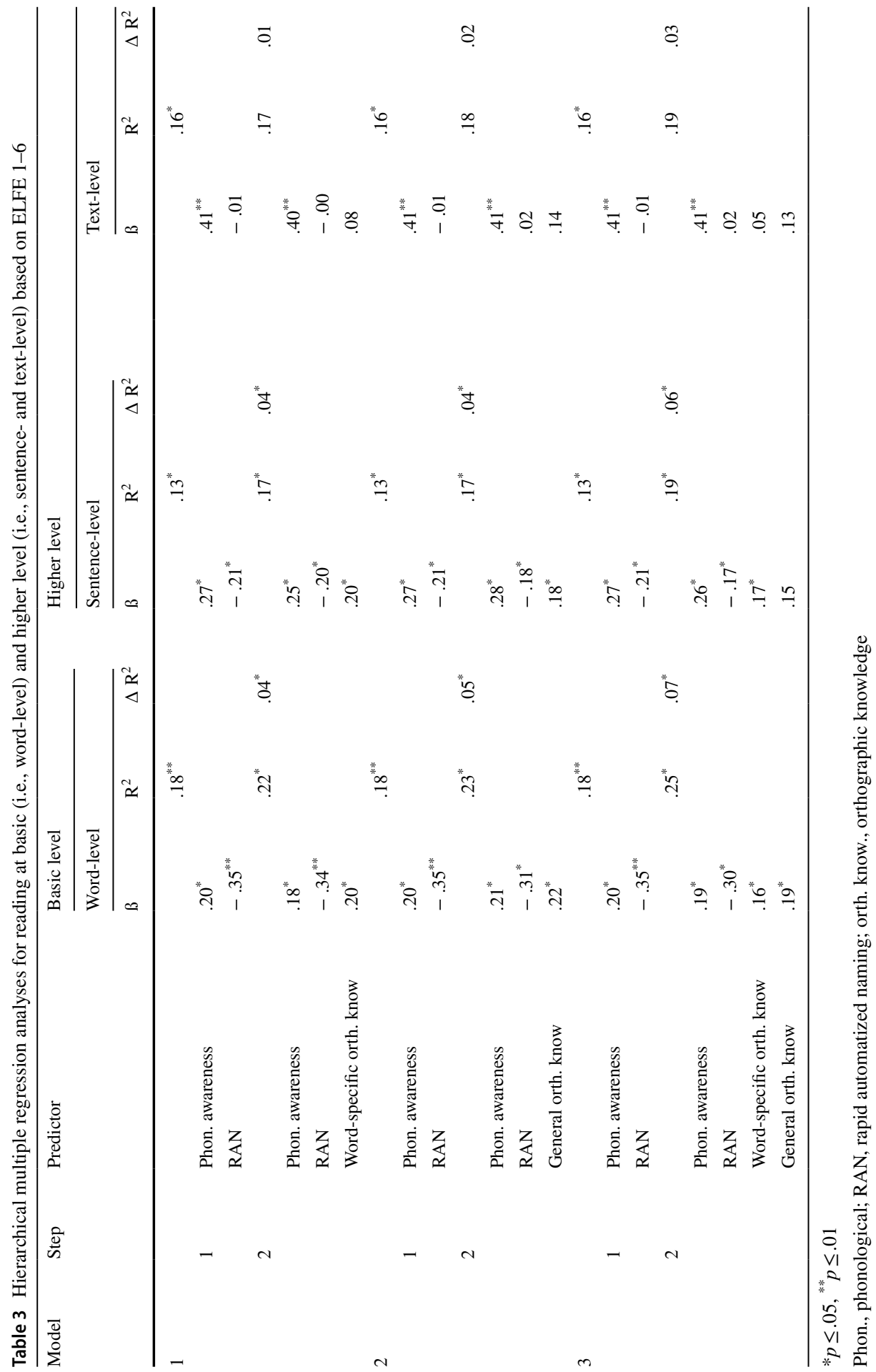


explain $13 \%$ of variance of sentence-level reading performance. After entering word-specific and/or general orthographic knowledge into the regression model, both phonological awareness and naming speed remain significant predictors. Word-specific (Table 3, Model 1, column Sentence-level) and general orthographic knowledge (Table 3, Model 2, column Sentence-level) each explain additional $4 \%$ of variance of reading at sentence-level. Together, word-specific and general orthographic knowledge explain additional $6 \%$ of variance of reading at sentence-level, over and above explained variance of phonological awareness and naming speed. However, when both components of orthographic knowledge are entered together in the model (Table 3, Model 3, column Sentence-level), general orthographic knowledge is no longer a significant predictor for reading at sentence-level.

The results show that phonological awareness is a significant predictor for reading performance at text-level explaining $16 \%$ of variance of text-level reading performance. After entering word-specific and/or general orthographic knowledge into the regression model, phonological awareness remains a significant predictor. However, neither naming speed (Table 3, Model 1 and 2, column Text-level), nor word-specific (Table 3, Model 1, column Text-level), nor general orthographic knowledge (Table 3, Model 2, column Text-level) are significant predictors of reading at text-level.

\section{Discussion}

The goal of this study was to determine whether word-specific and general orthographic knowledge contribute to basic level as well as to higher level reading processes among German elementary school children with poor reading proficiency, in addition to the well-established predictors phonological awareness and naming speed.

\section{Reading at basic level}

As assumed, the results show that both word-specific and general orthographic knowledge are significant predictors for reading at word-level, explaining additional variance to phonological awareness and naming speed among German poor reading children. The knowledge about word-specific representations as well as the knowledge about legal letter patterns stored in the mental lexicon are therefore important for word-reading processes. The results of the present study support previous reports (e.g., Conrad et al., 2013; Rothe et al., 2015; Zarić et al., 2020) and extend the evidence of the importance of orthographic knowledge for basic reading skill for children with poor reading proficiency. It can be assumed that poor readers use the memorized word-specific representations in order to recognize familiar/frequent words, and read them as a single unit, similar to the way typical readers do (Conrad et al., 2013). Since the knowledge about recurring spelling patterns, regularities, 
and consistencies (i.e., general orthographic knowledge) is considered to assist the memorization of specific letter combinations and units necessary to establish wordspecific representations in memory (Conrad et al., 2013), poor readers seem to use this knowledge when reading (novel/unknown) words.

The analyses also revealed that phonological awareness is a significant predictor for reading at word-level, which supports previous results (e.g., Vaessen \& Blomert, 2010). This is also in line with the Dual Route model (Coltheart et al., 1993), where phonological awareness is considered to be especially important for the recoding of low frequent and/or unknown words by using letter-to-sound conversion via the non-lexical route. Our sample consisted of German children with poor reading proficiency. It is assumed that they used the letter-to-sound conversion via the non-lexical route frequently, and therefore relied more on phonological awareness during reading than on word representation automatized retrieval via the lexical route (Wimmer, 1993). Thus, it is not surprising that in the present study phonological awareness was identified as a significant predictor for word-reading. Concerning the contribution of naming speed, the results show that naming speed is a significant predictor for word-reading, which is also compatible with previous results (e.g., Georgiou, Parrila et al., 2008). This might be taken as a support for the argument that efficient word-reading is supported through a quick retrieval of orthographic representations stored in the mental lexicon even among poor readers.

\section{Reading at higher level}

\section{Sentence-level comprehension}

In line with our expectations, the results show that word-specific and general orthographic knowledge predict reading comprehension at sentence-level, additionally to phonological awareness and naming speed. Sentence-reading requires the integration of the words within the sentence in order to comprehend the content (Castles et al., 2018). The knowledge about word-specific representations (i.e., word-specific orthographic knowledge) and the knowledge about legal letter patterns (i.e., general orthographic knowledge) support the automatized recognition and reading of single words, thus, enabling their quick processing. By doing so, more free resources are available for understanding the content of the sentence. However, considering the results of the regression model comprising both components of orthographic knowledge, it seems that the knowledge about the word-specific representations (i.e., word-specific orthographic knowledge) plays a more important role hereby than the knowledge about the legal positions of the double-consonants (i.e., general orthographic knowledge). It is possible that the items used to measure sentencelevel comprehension (see ELFE 1-6; Lenhard \& Schneider, 2006) comprise mostly of words which are familiar to the participants. Thus, they mainly relied on their word-specific knowledge in order to solve the task, and less on their general orthographic knowledge. However, when confronted with less familiar words, the participants used their general orthographic knowledge to solve the task. Therefore, when included separately in the regression model, both components of orthographic 
knowledge made a significant contribution. However, when considered simultaneously, only word-specific orthographic knowledge remained a significant predictor. This pattern was also found in children without reading difficulties (Zarić et al., 2020). Hence, it can be assumed that, regardless of the reading proficiency level, word-specific orthographic knowledge might have a larger influence for comprehension at sentence-level than general orthographic knowledge. Considering these results, future studies examining possible differential effects of both word-specific and general orthographic knowledge on reading are necessary.

The analyses also revealed that phonological awareness and naming speed are both significant contributors to reading comprehension at sentence-level. These results indicate that the awareness of letter-to-sound correspondences as well as the quick retrieval of words from the mental lexicon both not only support the single-word recognition, but also enable the comprehension at sentence-level in poor readers.

\section{Text-level comprehension}

Contrary to our expectations, the results revealed that word-specific and general orthographic knowledge do not contribute significantly to reading comprehension at text-level in German children with poor reading proficiency. Text-level comprehension comprises understanding of single words, for which word-specific and general orthographic knowledge play an important role as indicated by the present results. However, more complex processes, such as background knowledge and semantic skills are assumed to have a larger influence on text processing (Castles et al., 2018). Thus, the contribution of word-specific and general orthographic knowledge in reading at text-level might be not as relevant as the influence from more complex processes. These results are contrary to results found in a study by Katzir et al. (2006). They indicated that spelling recognition (i.e., recognition of the correct spelling out of four choices), which was operationalized in a similar way as word-specific knowledge in the present study, contributed significantly to comprehension of sentences and text-passages in reading impaired English children. However, in their study, Katzir et al. (2006) used a task for measuring sentence- and text-comprehension in which participants had to choose a word that fits the meaning of each sentence or passage. A comparable task was used in the present study to operationalize reading comprehension at sentence-level. Thus, it is possible that the task used in the study of Katzir et al. (2006) can better be compared to the present task measuring comprehension at sentence-level. In this case, the results of the present study would be in line with the findings from Katzir et al. (2006) regarding the previously mentioned reading comprehension at sentence-level. The results of the present study also deviate from those found in a recent study by Zarić et al. (2020). In this study, word-specific and general orthographic knowledge both contributed to reading comprehension at text-level in German typically skilled readers. One explanation for the divergent result pattern regarding text-level reading in the present study concerns the considered sample. Previous results (e.g., Constantinidou \& Stainthorp, 2009; Cornwall, 1992) indicated that phonological awareness seems to be critical for textpassage comprehension especially for reading impaired children. It is, therefore, 
possible that the poor readers of the present sample also relied more on other skills (e.g., phonological processing) when processing a text compared to typically skilled readers. This assumption was supported by our results, which revealed phonological awareness to be a significant predictor for reading comprehension at text-level in our sample.

Furthermore, again contrary to our expectations, naming speed was not identified to be a significant predictor for reading at text-level in poor readers. These results are in line with the results from Wolff (2014), indicating naming speed to be a significant predictor for reading speed, however, not for connected text comprehension (i.e., text-level reading comprehension) in reading impaired children. The results of the present study suggest that quick access to the representations stored in the mental lexicon facilitates reading of single words and understanding of the sentences. However, for higher reading processes, such as text-level comprehension, phonological processes can be considered to play a more important role in poor readers than naming speed. An alternative explanation concerns the way naming speed is measured. Neuhaus, Foorman, Francis, and Carlson (2001) suggest that when assessing naming speed, interest should be turned to the two RAN-components, namely the pause time (i.e., the sum of the length of pauses that are the intervals between the correctly sequenced articulations) and the articulation time (i.e., the sum of the length of all correctly articulated RAN stimuli). In the present study, the average reaction time per item per second of the four RAN subtests was used to operationalize naming speed. It is, however, possible that more differentiated RAN-scores, including the two components pause time and articulation time, might have provided more sophisticated information regarding the contribution of naming speed to reading processes on the text-level in children with reading difficulties. Further studies using more differentiated RAN-components should be considered to examine their relationship to basic and higher reading processes.

\section{Limitations}

Despite promising results, this study has at least four main limitations. We did not include an assessment of spelling and other reading-relevant components, such as morphological knowledge and awareness, listening comprehension, vocabulary knowledge or letter knowledge. These components were shown in previous studies to be important for basic as well as for higher reading processes (e.g., Verhoeven \& van Leeuwe, 2012; Volkmer, Schulte-Körne, \& Galuschka, 2019). By including more variables in future studies, we could better understand the relation patterns among a variety of components relevant for reading as well as their contribution to basic and higher reading processes. Furthermore, the current study was conducted with poor reading German-speaking children. Therefore, the generalization of these results to other orthographies and reading proficiency levels is restricted. One further limitation concerns the tasks used to measure word-specific and general orthographic knowledge. These two tasks consisted of a smaller number of items than originally intended once we conducted the item analysis. This indicates that further item improvement is necessary. An additional limitation concerns the task used to 
measure general intelligence in this study. We used an older version of the ZVT (Oswald \& Roth, 1987), which might have led to overestimation of the IQ of the sample. Future studies should either use the newer version of this test or some other non-verbal, time-efficient intelligence test.

\section{Summary and outlook}

The current study indicates that the knowledge about word-specific representations and legitimate letter patterns are important for word identification as well as for the understanding of relations between words in sentences in German poor readers, over and above phonological awareness and naming speed. However, these two components of orthographic knowledge do not seem to support any higher processes, such as text-level comprehension in poor readers. As mentioned before, reading includes a variety of processes. An impairment in one or more of these processes might result in reading deficits. The present study adds to the understanding of orthographic knowledge as one further component relevant for basic and some higher reading processes in poor readers. Acknowledging that impairments in orthographic knowledge skills might lead to reading deficits in some children (Badian, 2001), both wordspecific and general orthographic knowledge should be considered as relevant reading related predictors, as the present data reinforces. Regarding a practical application of the present results, it would be reasonable to develop a standardized test for measuring orthographic knowledge, and to use it in diagnostic procedures to reliably identify children at risk to develop reading difficulties. Another practical implication concerns the role of orthographic knowledge in a reading intervention. Since orthographic knowledge has an impact on reading performance, its assessment should be considered when applying a reading intervention, for instance a reading speed training. Assessment of orthographic knowledge might be helpful in understanding the underlying mechanism of such a reading intervention. The possible improvements in reading performance after applying a reading speed intervention might be a result of orthographic knowledge enhancement during the intervention. It is also possible that the initial orthographic knowledge proficiency level at the onset of the intervention might have an influence on training effects - children with better orthographic knowledge proficiency level might benefit more from such a reading intervention. As shown by Berninger et al., (1999), orthographic skills were shown to differentiate between reading intervention outcomes, thus, they should be included in future studies when measuring reading trainings effects.

\section{Appendix}

See Tables 4, 5 and 6. 
Table 4 Items of the task measuring word-specific orthographic knowledge (words and pseudohomophones)

\begin{tabular}{lll}
\hline Word & \multicolumn{2}{l}{ Pseudohomophone } \\
\cline { 2 - 3 } & & Original word \\
\hline Aal $^{\mathrm{a}}$ [eel] & fättig $^{\mathrm{a}}$ & fettig [greasy] \\
ähnlich [similar] & ainsam $^{\text {einsam [lonely] }}$ \\
ändern [to change] & bezaalen & bezahlen [to pay] \\
Bahn* [train] & fäucht* & feucht [moist] \\
Beil* [axe] & Feeler* & Fehler [failure] \\
Beule* [dent] & Gaist & Geist [ghost] \\
Bier* [beer] & gemain & gemein [nasty] \\
Fee [fairy] & Hächt* & Hecht [pike] \\
friedlich* [peaceful] & haiß & heiß [hot] \\
Haufen* [pile] & Kaffeh & Kaffee [coffee] \\
hohl* [hollow] & Kaim* & Keim [germ] \\
Leim [size] & Raifen & Reifen [tire] \\
mächtig [mighty] & Schaibe & Scheibe [slice] \\
Nest* [nest] & stail & steil [steep] \\
Pech [misfortune] & zaam* & zahm [tame] \\
weich* [soft] & Zaitung & Zeitung [newspaper] \\
\hline
\end{tabular}

${ }^{\text {a }}$ Practice item

${ }^{\mathrm{b}}$ Original, real words used for creating pseudohomophones

*Words and pseudohomophones excluded after the item-analysis 
Table 5 Items of the task measuring general orthographic knowledge-knowledge about legal positions of double consonants

\begin{tabular}{|c|c|c|c|c|c|}
\hline \multicolumn{3}{|l|}{ Legal } & \multicolumn{3}{|l|}{ Illegal } \\
\hline Stimuli & Bigram freq. & Trigram freq. & Stimuli & Bigram freq. & Trigram freq. \\
\hline fahopp & 209,152 & 9611 & ffahop & 218,147 & 7322 \\
\hline fosupp & 118,094 & 4964 & ffosup & 127,089 & 1044 \\
\hline fuppat & 232,213 & 5276 & ffupat & 241,208 & 876 \\
\hline lannag & 927,832 & 112,628 & llanag & 932,796 & 39,967 \\
\hline leminn & $1,412,114$ & 29,622 & llemin & 905,998 & 97,451 \\
\hline linnur & $1,244,304$ & 54,952 & llinur & $1,249,268$ & 56,678 \\
\hline lodenn* & $2,147,677$ & 258,604 & lloden* & $2,152,641$ & 212,635 \\
\hline mattel $^{*}$ & $1,475,675$ & 196,837 & mmatel $^{*}$ & $1,441,786$ & 45,208 \\
\hline misett & 873,142 & 46,826 & mmiset & 839,253 & 30,426 \\
\hline mugott & 251,696 & 9610 & mmugot & 217,807 & 1330 \\
\hline nellus* & 996,278 & 57,524 & nnelus $^{*}$ & 991,314 & 51,863 \\
\hline nillau & 900,006 & 54,367 & nnilau & 895,042 & 30,282 \\
\hline nomell & 706,712 & 63,128 & nnomel & 701,748 & 20,619 \\
\hline paffab & 242,943 & 6116 & ppafab & 233,948 & 1177 \\
\hline pasaff $^{*}$ & 508,841 & 12,790 & ppasaf $^{*}$ & 499,846 & 7644 \\
\hline pateff & $1,111,250$ & 18,167 & ppatef & $1,102,255$ & 16,520 \\
\hline puffan & 608,541 & 11,744 & ppufan & 599,546 & 9418 \\
\hline tammit & 610,325 & 98,796 & ttamit & 644,214 & 93,110 \\
\hline timmac & 531,645 & 84,176 & ttimac & 565,534 & 41,395 \\
\hline tokamm & 289,750 & 31,979 & ttokam & 323,639 & 15,464 \\
\hline
\end{tabular}

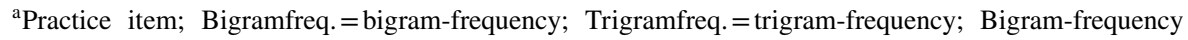
and trigram-frequency show the mean cumulated percentage of occurrence per million continuous words in the corpus within the childLex-database

*Pseudoword-pairs excluded after item-analysis 


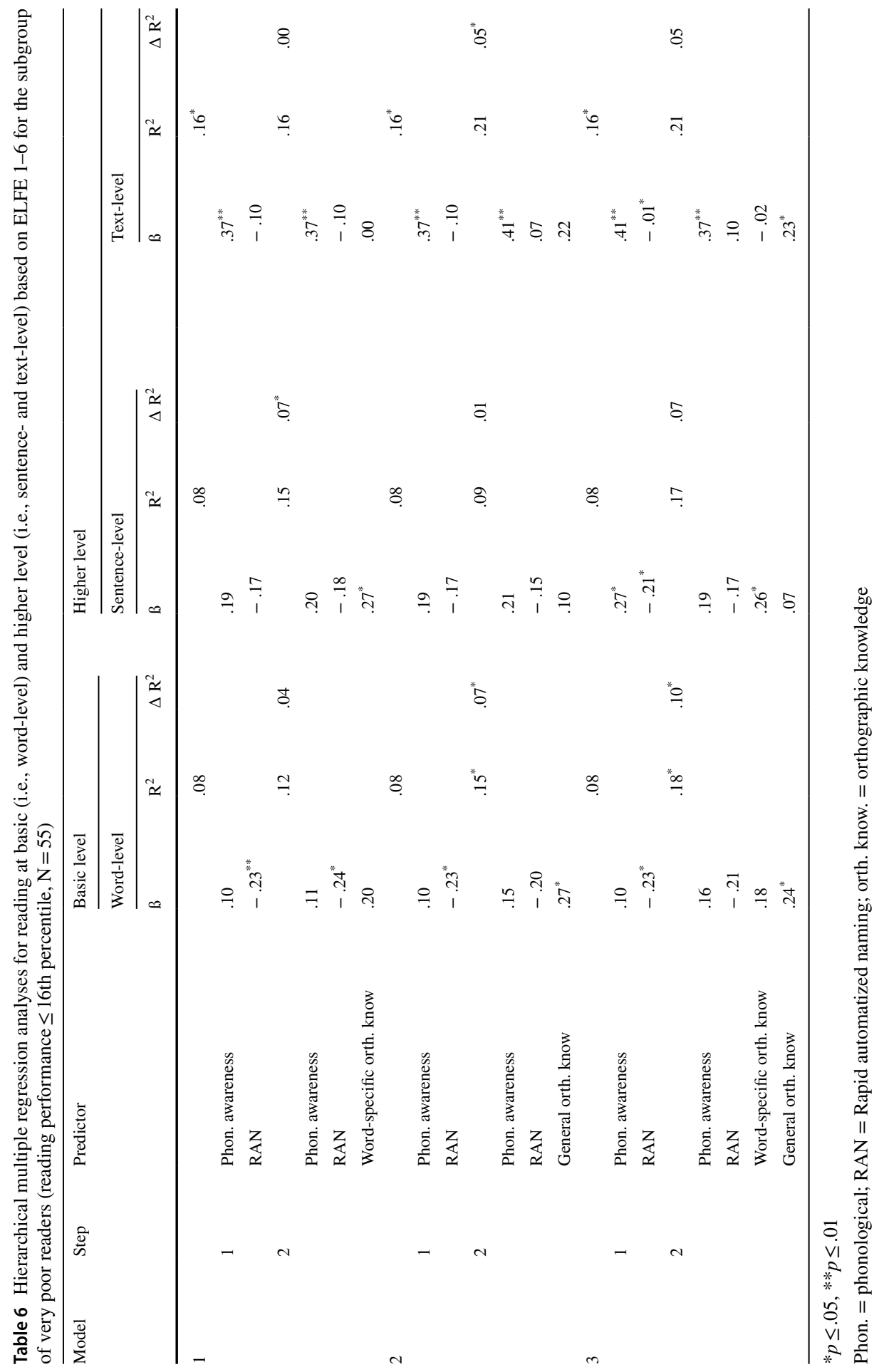


Funding Open Access funding enabled and organized by Projekt DEAL.

\section{Compliance with ethical standards}

Conflict of interest The authors declare that they have no conflict of interest.

Open Access This article is licensed under a Creative Commons Attribution 4.0 International License, which permits use, sharing, adaptation, distribution and reproduction in any medium or format, as long as you give appropriate credit to the original author(s) and the source, provide a link to the Creative Commons licence, and indicate if changes were made. The images or other third party material in this article are included in the article's Creative Commons licence, unless indicated otherwise in a credit line to the material. If material is not included in the article's Creative Commons licence and your intended use is not permitted by statutory regulation or exceeds the permitted use, you will need to obtain permission directly from the copyright holder. To view a copy of this licence, visit http://creativecommons.org/licen ses/by/4.0/.

\section{References}

Anthony, J. L., \& Francis, D. J. (2005). Development of phonological awareness. Current Directions in Psychological Science, 14(5), 255-259.

Apel, K. (2011). What is orthographic knowledge? Language, Speech, and Hearing Services in Schools, 42(4), 592-603. https://doi.org/10.1044/0161-1461(2011/10-0085).

Apel, K., Henbest, V. S., \& Masterson, J. (2018). Orthographic knowledge: Clarifications, challenges, and future directions. Reading and Writing, 32, 873-889. 10.1007/s11145-018-9895-9.

Arab-Moghaddam, N., \& Sénéchal, M. (2001). Orthographic and phonological processing skills in reading and spelling in Persian/English bilinguals. International Journal of Behavioral Development, 25(2), 140-147. https://doi.org/10.1080/01650250042000320.

Arnell, K. M., Joanisse, M. F., Klein, R. M., Busseri, M. A., \& Tannock, R. (2009). Decomposing the relation between rapid automatized naming (RAN) and reading ability. Journal of Experimental Psychology, 63(3), 173-184.

Bäcker, A., \& Neuhäuser, G. (2003). Internalisierende und externalisiserende Syndrome bei Leseund Rechtschreibstörungen (Internalized and externalized syndroms in dyslexia). Praxis der Kinderpsychologie und Kinderpsychiatrie, 52(8), 329-337.

Badian, N. A. (2001). Phonological and orthographic processing: Their roles in reading prediction. Annals of Dyslexia, 51, 179-202.

Bergmann, J., \& Wimmer, H. (2008). A dual-route perspective on poor reading in a regular orthography: Evidence from phonological and orthographic lexical decisions. Cognitive Neuropsychology, 25(5), 653-676. https://doi.org/10.1080/02643290802221404.

Berninger, V. W., Abbott, R. D., Zook, D., Ogier, S., Lemos-Britton, Z., \& Brooksher, R. (1999). Early intervention for reading disabilities: Teaching the alphabet principle in a connectionist framework. Journal of Learning Disabilities, 32(6), 491-503.

Bowers, P. G. (1995). Tracing symbol naming speed's unique contributions to reading disability over time. Reading and Writing: An Interdisciplinary Journal, 7(2), 189-216.

Brunner, M., Seibert, A., Dierks, A., \& Körkel, B. (1999). Heidelberger Lautdifferenzierungstest H-LAD. Prüfung der auditiv-kinästhetischen Wahrnehmung zur Differenzierung der Ursachen bei Lese- und Rechtschreibschwäche (A sound differentiation test HLAD. Testing of auditiv-kinesthetic perception for differentiating the causes in reading and spelling difficulties). Heidelberg, Germany: Westra.

Cain, K. (2009). Children's reading comprehension difficulties. In: C. Wood \& V. Connely (Eds.), Contemporary perspectives on reading and spelling (pp. 59-75). London, UK: Routledge.

Carroll, J. M., Maughan, B., Goodman, R., \& Meltzer, H. (2005). Literacy difficulties and psychiatric disorders: Evidence for comorbidity. Journal of Child Psychology and Psychiatry and Allied Disciplines, 46(5), 524-532. https://doi.org/10.1111/j.1469-7610.2004.00366.x. 
Castles, A., Rastle, K., \& Nation, K. (2018). Ending the reading wars: Reading acquisition from novice to expert. Psychological Science in the Public Interest, 19, 5-51. https://doi.org/10.1177/15291 00618772271.

Coltheart, M., Curtis, B., Atkins, P., \& Haller, M. (1993). Models of reading aloud: Dual-route model and parallel-distributed-processing approaches. Psychological Review, 100, 589-608.

Conrad, N. J., Harris, N., \& Williams, J. (2013). Individual differences in children's literacy development: The contribution of orthographic knowledge. Reading and Writing, 26(8), 1223-1239. https://doi.org/10.1007/s11145-012-9415-2.

Constantinidou, M., \& Stainthorp, R. (2009). Phonological awareness and reading speed deficits in reading disabled Greek-speaking children. Educational Psychology, 29(2), 171-186. https://doi. org/10.1080/01443410802613483.

Cornwall, A. (1992). The relationship of phonological awareness, rapid naming, and verbal memory to severe reading and spelling disability. Journal of Learning Disabilities, 25(8), 532-538. https://doi. org/10.1177/002221949202500808.

Cutting, L. E., \& Denckla, M. B. (2001). The relationship of serial rapid naming and word reading in normally developing readers: An exploratory model. Reading and Writing, 14, 673-705.

De Jong, P. F., \& Messbauer, V. C. S. (2011). Orthographic context and the acquisition of orthographic knowledge in normal and dyslexic readers. Dyslexia, 17(2), 107-122. https://doi.org/10.1002/ dys.427.

Denckla, M. B., \& Rudel, R. G. (1976). Rapid 'automatized' naming (R.A.N.): Dyslexia differentiated from other learning disabilities. Neuropsychologia, 14(4), 471-479. https://doi.org/10.1016/00283932(76)90075-0.

Ehri, L. C. (2005). Learning to read words: Theory, findings, and issues. Scientific Studies of Reading, 9(2), 167-188. https://doi.org/10.1207/s1532799xssr0902_4.

Ehri, L. C. (2014). Orthographic mapping in the acquisition of sight word reading, spelling memory, and vocabulary learning. Scientific Studies of Reading, 18(1), 5-21. https://doi.org/10.1080/10888 438.2013.819356.

Ennemoser, M., Marx, P., Weber, J., \& Schneider, W. (2012). Spezifische Vorläuferfertigkeiten der Lesegeschwindigkeit, des Leseverständnisses und des Rechtschreibens (Specific precursor skills of reading speed, reading comprehension and spelling). Zeitschrift für Entwicklungspsychologie und Pädagogische Psychologie, 44(2), 53-67. https://doi.org/10.1026/0049-8637/a000057.

Fuchs, L. S., Fuchs, D., Hosp, M. K., \& Jenkins, J. R. (2001). Oral reading fluency as an indicator of reading competence: A theoretical, empirical, and historical analysis. Scientific Studies of Reading, 5(3), 239-256. https://doi.org/10.4324/9781410608246-3.

Georgiou, G. K., Das, J. P., \& Hayward, D. V. (2008). Comparing the contribution of two tests of working memory to reading in relation to phonological awareness and rapid naming speed. Journal of Research in Reading, 31(3), 302-318.

Georgiou, G. K., Papadopoulos, T. C., Fella, A., \& Parrila, R. (2012). Rapid naming speed components and reading development in a consistent orthography. Journal of Experimental Child Psychology, 112(1), 1-17. https://doi.org/10.1016/j.jecp.2011.11.006.

Georgiou, G. K., Parrila, R., \& Papadopoulos, T. C. (2008). Predictors of word decoding and reading fluency across languages varying in orthographic consistency. Journal of Educational Psychology, 100(3), 566-580. https://doi.org/10.1037/0022-0663.100.3.566.

Goswami, U. (2002). Phonology, reading development, and dyslexia: A cross-linguistic perspective. Annals of Dyslexia, 52, 141-163.

Gough, P. B., \& Tunmer, W. E. (1986). Decoding, reading, and reading disability. Remedial and Special Education, 7(1), 6-10. https://doi.org/10.1177/074193258600700104.

Heath, S. M., \& Hogben, J. H. (2004). Cost-effective prediction of reading difficulties. Journal of Speech Language and Hearing Research, 47(4), 751-765. https://doi.org/10.1044/1092-4388(2004/057).

Ise, E., Arnoldi, C. J., \& Schulte-Körne, G. (2014). Development of orthographic knowledge in Germanspeaking children: A 2-year longitudinal study. Journal of Research in Reading, 37(3), 233-249. https://doi.org/10.1111/j.1467-9817.2012.01535.x.

Karageorgos, P., Müller, B., \& Richter, T. (2019). Modelling the relationship of accurate and fluent word recognition in primary school. Learning and Individual Differences, 76, 101779. https://doi. org/10.1016/j.lindif.2019.101779.

Katz, L., \& Frost, R. (1992). The reading process is different for different orthographies: The orthographic depth hypothesis. In: R. Frost \& L. Katz (Eds.), Orthography, phonology, morphology, 
and meaning (pp. 67-84). Amsterdam, The Netherlands: Elsevier North Holland Press. https://doi. org/10.1016/S0166-4115(08)62789-2.

Katzir, T., Kim, Y., Wolf, M., Kennedy, B., Lovett, M., \& Morris, R. (2006). The relationship of spelling recognition, RAN, and phonological awareness to reading skills in older poor readers and younger reading-matched controls. Reading and Writing, 19(8), 845-872. https://doi.org/10.1007/s1114 5-006-9013-2.

Kirby, J. R., Parrila, R., \& Pfeiffer, S. (2003). Naming speed and phonological awareness as predictors of reading development. Journal of Educational Psychology, 95(3), 453-464.

LaBerge, D., \& Samuels, S. J. (1974). Toward a theory of automatic information processing in reading. Cognitive Psychology, 6, 293-323.

Landerl, K., \& Moll, K. (2010). Comorbidity of learning disorders: Prevalence and familial transmission. Journal of Child Psychology and Psychiatry and Allied Disciplines, 51(3), 287-294. https://doi.org/ 10.1111/j.1469-7610.2009.02164.x.

Landerl, K., \& Thaler, V. (2006). Reading and spelling acquisition and dyslexia in German. In R. M. Joshi \& P. G. Aaron (Eds.), Handbook of orthography and literacy (pp. 121-134). Mahwah, NJ: Erlbaum.

Landerl, K., \& Wimmer, H. (2008). Development of word reading fluency and spelling in a consistent orthography: An 8-year follow-up. Journal of Educational Psychology, 100(1), 150-161. https://doi. org/10.1037/0022-0663.100.1.150.

Lenhard, W., \& Schneider, W. (2006). Ein Leseverständnistest für Erst- bis Sechstklässler (A reading comprehension test for first- till sixt-graders). Göttingen, Germany: Hogrefe.

Linder, M., \& Grissemann, H. (2000). Züricher Lesetest (Züricher reading test). Bern, Switzerland: Huber.

Loveall, S. J., Channell, M. M., Phillips, B. A., \& Conners, F. A. (2013). Phonological recoding, rapid automatized naming, and orthographic knowledge. Journal of Experimental Child Psychology, 116(3), 738-746. https://doi.org/10.1016/j.jecp.2013.05.009.

McCallum, R. S., Bell, S. M., Wood, M. S., Below, J. L., Choate, S. M., \& McCane, S. J. (2006). What is the role of working memory in reading relative to the big three processing variables (orthography, phonology, and rapid naming)? Journal of Psychoeducational Assessment, 24(3), 243-259.

Melby-Lervåg, M., Lyster, S.-A.H., \& Hulme, C. (2012). Phonological skills and their role in learning to read: A meta-analytic review. Psychological Bulletin, 138, 322-352.

Moll, K., Fussenegger, B., Willburger, E., \& Landerl, K. (2009). RAN is not a measure of orthographic processing. Evidence from the asymmetric German orthography. Scientific Studies of Reading, 13(1), 1-25. https://doi.org/10.1080/10888430802631684.

Moll, K., Kunze, S., Neuhoff, N., Bruder, J., \& Schulte-Körne, G. (2014). Specific learning disorder: Prevalence and gender differences. PLOS ONE, 9(7), 1-8. https://doi.org/10.1371/journ al.pone.0103537.

Moll, K., Wallner, R., \& Landerl, K. (2012). Kognitive Korrelate der Lese-, Leserechtschreib- und der Rechtschreibstörung (Cognitive correlates of reading and spelling disorder). Lernen und Lernstörungen, 1(1), 7-19. https://doi.org/10.1024/2235-0977/a000002.

Neuhaus, G., Foorman, B. R., Francis, D. J., \& Carlson, C. D. (2001). Measures of information processing in rapid automatized naming (RAN) and their relation to reading. Journal of Experimental Child Psychology, 78, 359-373.

Oswald, W. D., \& Roth, E. (1987). Der Zahlen-Verbindungs-Test (ZVT). Ein sprachfreier Intelligenztest zur Messung der kognitiven Leistungsgeschwindigkeit (2. Überarbeitung; A number-connecting test. A verbal-free intelligence test for measuring cognitive processing speed ( $2^{\text {nd }}$ edition). Göttingen, Germany: Hogrefe.

Paulesu, E., Démonet, J.-F., Fazio, F., McCrory, E., Chanoine, V., Brunswick, N., \& Al, E. (2001). Dyslexia: Cultural diversity and biological unity. Science, 291, 2165-2167.

Peirce, J. W. (2009). Generating stimuli for neuroscience using PsychoPy. Frontiers in Neuroinformatics, 2(10), 1-8. https://doi.org/10.3389/neuro.11.010.2008.

Perfetti, C. A., \& Hart, L. (2002). The lexical quality hypothesis. Precursors of Functional Literacy. https ://doi.org/10.1075/swll.11.14per.

Perfetti, C. A., Landi, N., \& Oakhill, J. (2005). The acquisition of reading comprehension skill. In: M. J. Snowling \& C. Hulme (Eds.), The science of reading: A handbook (pp. 227-247). Oxford, UK: Blackwell.

Perfetti, C. A. (1985). Reading ability. New York, NY: Oxford University Press. 
Pfost, M. (2015). Children's phonological awareness as a predictor of reading and spelling: A systematic review of longitudinal research in German-speaking countries. Zeitschrift für Entwicklungspsychologie und Pädagogische Psychologie, 47(3), 123-138. https://doi.org/10.1026/0049-8637/a000141.

Pikulski, J., \& Chard, D. J. (2005). Fluency: Bridge between decoding and reading comprehension. The Reading Teacher, 58, 510-519.

Ramus, F., Rosen, S., Dakin, S.-C., Day, B.-L., Castellote, J.-M., \& White, S. (2003). Theories of developmental dyslexia: Insights from a multiple case study of dyslexic adults. Brain: A Journal of Neurology, 126(4), 841-865.

Richter, T., \& Christmann, U. (2002). Lesekompetenz: Prozessebenen und interindividuelle Unterschiede (Reading competence: processing levels and interindividual differences). In: N. Groeben \& B. Humelmann (Eds.), Lesekompetenz: Bedingungen, Dimensionen, Funktionen (Reading competence: Conditions, dimensions, functions (pp. 25-58). Weinheim, Germany: Juventa.

Roberts, G., Good, R., \& Corcoran, S. (2005). Story retell: A fluency-based indicator of reading comprehension. School Psychology Quarterly, 20(3), 304-317. https://doi.org/10.1521/scpq.2005.20.3.304.

Rothe, J., Cornell, S., Ise, E., \& Schulte-Körne, G. (2015). A comparison of orthographic processing in children with and without reading and spelling disorder in a regular orthography. Reading and Writing, 28(9), 1307-1332. https://doi.org/10.1007/s11145-015-9572-1.

Rothe, J., Schulte-Körne, G., \& Ise, E. (2014). Does sensitivity to orthographic regularities influence reading and spelling acquisition? A 1-year prospective study. Reading and Writing, 27(7), 11411161. https://doi.org/10.1007/s11145-013-9479-7.

Scheerer-Neumann, G. (2015). Lese-Rechtschreib-Schwäche und Legasthenie. Grundlagen, Diagnostik und Förderung (Reading and spelling difficulties and dyslexia. Basics, diagnosis, and fostering). Stuttgart, Germany: Kohlhammer.

Schneider, W., Blanke, I., Faust, V., \& Küspert, P. (2011). Würzburger Leise Leseprobe-Revision (Würzburger silent reading test- revision). Göttingen, Germany: Hogrefe.

Schroeder, S., Würzner, K.-M., Heister, J., Geyken, A., \& Kliegl, R. (2015). childLex: A lexical database of German read by children. Behavior Research Methods, 47(4), 1085-1094. https://doi. org/10.3758/s13428-014-0528-1.

Seymour, P. H. K., Aro, M., \& Erskine, J. M. (2003). Foundation literacy acquisition in European orthographies. British Journal of Psychology, 94, 143-174.

Steinbrink, C., \& Lachmann, T. (2014). Lese-Rechtschreibstörung. Grundlagen, Diagnostik, Intervention (Reading and spelling disorder. Basics, diagnosis, intervention). Berlin, Germany: Springer. https:// doi.org/10.1017/CBO9781107415324.004.

Swanson, H. L., Trainin, G., Necoechea, D. M., \& Hammill, D. D. (2003). Rapid naming, phonological awareness, and reading: A meta-analysis of the correlation evidence. Review of Educational Research, 73(4), 407-440. https://doi.org/10.3102/00346543073004407.

Taraban, R., \& McClelland, J. L. (1990). Parsing and comprehension: A multiple-contraint view. In: D. A. Ballota, G. B. Flores d'Arcais, \& K. Rayner (Eds.), Comprehension processes in reading (pp. 231-264). Hillsdale, NJ: Lawrence Erlbaum Associates.

Thaler, V., Ebner, E. M., Wimmer, H., \& Landerl, K. (2004). Training reading fluency in dysfluent readers with high reading accuracy: Word specific effects but low transfer to untrained words. Annals of Dyslexia, 54, 89-113.

Tippelt, R., \& Schmidt-Hertha, B. (2018). Handbuch Bildungsforschung (Manual of educational research). Wiesbaden, Germany: Springer Fachmedien.

Vaessen, A., \& Blomert, L. (2010). Long-term cognitive dynamics of fluent reading development. Journal of Experimental Child Psychology, 105(3), 213-231.

Valtin, R. (2017). Einordnung der IGLU-2016-Befunde in das europäische Rahmenkonzept für gute Leseförderung, Kapitel XII (Results from the study IGLU from 2016 regarding good reading fostering, chapter XII). In: A. Hußmann, W. Bos, A. Bremerich-Vos, D. Kasper, E.-M. Lankes, N. McElvany, ... R. Valtin (Eds.), IGLU 2016. Lesekompetenzen von Grundschulkindern im internationalen Vergleich (IGLU 2016. Reading competence in elementary school children in an international comparison; ) (pp. 315-328). Münster, Germany.

Vellutino, F. R., Scanlon, D. M., Sipay, E. R., Small, S. G., Pratt, A., Chen, R., \& Denckla, M. B. (1996). Cognitive profiles of difficult-to-remediate and readily remediated poor readers: Early intervention as a vehicle for distinguishing between cognitive and experiential deficits as basic causes of specific reading disability. Journal of Educational Psychology, 88(4), 601-638. 
Vellutino, F. R., Fletcher, J. M., Snowling, M. J., \& Scanlon, D. M. (2004). Specific reading disability (dyslexia): What have we learned in the past four decades? Journal of Child Psychology and Psychiatry, and Allied Disciplines, 45(1), 2-40.

Vellutino, F. R., Tunmer, W. E., Jaccard, J. J., \& Chen, R. (2007). Components of reading ability: Multivariate evidence for a convergent skills model of reading development. Scientific Studies of Reading, 11(1), 3-32. https://doi.org/10.1080/10888430709336632.

Verhoeven, L., \& van Leeuwe, J. (2012). The simple view of second language reading throughout the primary grades. Reading and Writing, 25, 1805-1818.

Volkmer, S., Schulte-Körne, G., \& Galuschka, K. (2019). Die Rolle der morphologischen Bewusstheit bei Lese- und Rechtschreibleistungen (The role of morphological awareness in reading and spelling abilities). Zeitschrift für Kinder- und Jugendpsychiatrie und Psychotherapie, 47(4), 334-344. https ://doi.org/10.1024/1422-4917/a000652.

Willcutt, E. G., \& Pennington, B. F. (2000). Psychiatric comorbidity in children and adolescents. Journal of Child Psychology and Psychiatry, 18(8), 1039-1048. https://doi.org/10.1097/01.yco.0000172063 .78649.66.

Wimmer, H. (1993). Characteristics of developmental dyslexia in a regular writing system. Applied Psycholinguistics, 14(1), 1-33.

Wolf, M., \& Bowers, P. G. (1999). The double-deficit hypothesis for the developmental dyslexias. Journal of Educational Psychology, 91(3), 415-438.

Wolf, M., \& Katzir-Cohen, T. (2001). Reading fluency and its intervention. Scientific Studies of Reading, 5, 211-239.

Wolff, U. (2014). RAN as a predictor of reading skills, and vice versa: Results from a randomised reading intervention. Annals of Dyslexia, 64(2), 151-165. https://doi.org/10.1007/s11881-014-0091-6.

Zarić, J., Hasselhorn, M., \& Nagler, T. (2020). Orthographic knowledge predicts reading and spelling skills over and above general intelligence and phonological awareness. European Journal of Psychology of Education. https://doi.org/10.1007/s10212-020-00464-7.

Ziegler, J. C., Bertrand, D., Tóth, D., Csépe, V., Reis, A., Faísca, L., ... BlomertBlomert, L. L. (2010). Orthographic depth and its impact on universal predictors of reading: A cross-language investigation. Psychological Science, 21(4), 551-559. https://doi.org/10.1177/0956797610363406.

Ziegler, J. C., \& Goswami, U. (2005). Reading acquisition, developmental dyslexia, and skilled reading across languages: A psycholinguistic grain size theory. Psychological Bulletin, 131(1), 3-29. https:// doi.org/10.1037/0033-2909.131.1.3.

Publisher's Note Springer Nature remains neutral with regard to jurisdictional claims in published maps and institutional affiliations. 